University of Nebraska - Lincoln

DigitalCommons@University of Nebraska - Lincoln

2012

\title{
Assimilation of GRACE terrestrial water storage into a land surface model: Evaluation and potential value for drought monitoring in western and central Europe
}

\author{
Bailing Li \\ University of Maryland \\ Matthew Rodell \\ NASA Goddard Space Flight Center \\ Benjamin F. Zaitchik \\ Johns Hopkins University \\ Rolf H. Reichle \\ NASA Goddard Space Flight Center \\ Randal D. Koster \\ NASA Goddard Space Flight Center \\ See next page for additional authors
}

Follow this and additional works at: https://digitalcommons.unl.edu/nasapub

Part of the Physical Sciences and Mathematics Commons

Li, Bailing; Rodell, Matthew; Zaitchik, Benjamin F.; Reichle, Rolf H.; Koster, Randal D.; and van Dam, Tonie M., "Assimilation of GRACE terrestrial water storage into a land surface model: Evaluation and potential value for drought monitoring in western and central Europe" (2012). NASA Publications. 67.

https://digitalcommons.unl.edu/nasapub/67

This Article is brought to you for free and open access by the National Aeronautics and Space Administration at DigitalCommons@University of Nebraska - Lincoln. It has been accepted for inclusion in NASA Publications by an authorized administrator of DigitalCommons@University of Nebraska - Lincoln. 


\section{Authors}

Bailing Li, Matthew Rodell, Benjamin F. Zaitchik, Rolf H. Reichle, Randal D. Koster, and Tonie M. van Dam 


\title{
Assimilation of GRACE terrestrial water storage into a land surface model: Evaluation and potential value for drought monitoring in western and central Europe
}

\author{
Bailing Li ${ }^{\text {a,b,* }}$, Matthew Rodell ${ }^{\mathrm{b}}$, Benjamin F. Zaitchik ${ }^{\mathrm{c}}$, Rolf H. Reichle ${ }^{\mathrm{d}}$, Randal D. Koster ${ }^{\mathrm{d}}$, \\ Tonie M. van Dam ${ }^{\mathrm{e}}$
}

${ }^{a}$ Earth System Science Interdisciplinary Center, University of Maryland, College Park, MD 20740, USA

${ }^{\mathrm{b}}$ Hydrological Sciences Laboratory, NASA Goddard Space Flight Center, Greenbelt, MD 20771, USA

${ }^{\mathrm{c}}$ Department of Earth and Planetary Sciences, Johns Hopkins University, Baltimore, MD 21218, USA

${ }^{\mathrm{d}}$ Global Modeling and Assimilation Office, NASA Goddard Space Flight Center, Greenbelt, MD 20771, USA

e Department of Physics and Material Sciences, University of Luxembourg, L-1359 Luxembourg, Luxembourg

\section{A R T I C L E I N F O}

\section{Article history:}

Received 14 November 2011

Received in revised form 22 March 2012

Accepted 20 April 2012

Available online $\mathrm{xxxx}$

This manuscript was handled by P. Baveye,

Editor-in-Chief, with the assistance of

Magdeline Laba, Associate Editor

\section{Keywords:}

GRACE terrestrial water storage

Data assimilation

Runoff

Groundwater

Soil moisture

\begin{abstract}
S U M M A R Y
A land surface model's ability to simulate states (e.g., soil moisture) and fluxes (e.g., runoff) is limited by uncertainties in meteorological forcing and parameter inputs as well as inadequacies in model physics. In this study, anomalies of terrestrial water storage (TWS) observed by the Gravity Recovery and Climate Experiment (GRACE) satellite mission were assimilated into the NASA Catchment land surface model in western and central Europe for a 7-year period, using a previously developed ensemble Kalman smoother. GRACE data assimilation led to improved runoff estimates (in temporal correlation and root mean square error) in 17 out of 18 hydrological basins, even in basins smaller than the effective resolution of GRACE. Improvements in root zone soil moisture were less conclusive, partly due to the shortness of the in situ data record. GRACE data assimilation also had significant impacts in groundwater estimates including trend and seasonality. In addition to improving temporal correlations, GRACE data assimilation also reduced increasing trends in simulated monthly TWS and runoff associated with increasing rates of precipitation. The assimilation downscaled (in space and time) and disaggregated GRACE data into finer scale components of TWS which exhibited significant changes in their dryness rankings relative to those without data assimilation, suggesting that GRACE data assimilation could have a substantial impact on drought monitoring. Signals of drought in GRACE TWS correlated well with MODIS Normalized Difference Vegetation Index (NDVI) data in most areas. Although they detected the same droughts during warm seasons, drought signatures in GRACE derived TWS exhibited greater persistence than those in NDVI throughout all seasons, in part due to limitations associated with the seasonality of vegetation. Mass imbalances associated with GRACE data assimilation and challenges of using GRACE data for drought monitoring are discussed.
\end{abstract}

(c) 2012 Elsevier B.V. All rights reserved.

\section{Introduction}

Seasonal and interannual variability in terrestrial water storage (TWS) is of critical interest in water resource analysis and seasonal hydrological forecasts because TWS-which includes soil moisture, groundwater, surface water and snow-is an important hydrological indicator in its own right: volume of water stored in snowpack or groundwater, for example, reflects present hydrological conditions and can be used to infer the potential for future hydrological

\footnotetext{
* Corresponding author at: Earth System Science Interdisciplinary Center, University of Maryland, College Park, MD 20740, USA. Tel.: +1 301286 6020; fax: +1 3016145808.

E-mail address: Bailing.li@nasa.gov (B. Li).
}

stress. TWS is also important because of its role in other aspects of the hydrological cycle. Its status can affect infiltration rates and subsurface flow, with associated impacts on runoff and recharge rates. TWS anomalies can also affect the hydrological cycle through soil moisture feedbacks on the atmosphere. One of the important aspects of TWS is its unique dynamics. Soil moisture and groundwater are low-pass filters on the terrestrial hydrological cycle that gradually remove high frequency variability associated with atmospheric forcing as depth increases (Eltahir and Yeh, 1999; Wu et al., 2002). This dynamic means that TWS acts as a "memory" component of the terrestrial hydrological cycle, with implications for land-atmosphere interactions (Koster and Suarez, 2001) and predictability in certain regions (Dirmeyer, 2000; Dirmeyer et al., 2009; Koster et al., 2000b, 2010). 
Interactions among components of TWS not only re-distribute water spatially but also increase the complexity of the hydrological cycle. Groundwater, which accounts for a major part of TWS (Rodell and Famiglietti, 2001; Rodell et al., 2007; Yeh et al., 2006), has a strong inter-dependency with stream flow (Eltahir and Yeh, 1999; Zampieri et al., 2012). This connection, combined with the long memory of groundwater variability, means that accurate information on groundwater can contribute significant skills to seasonal river discharge forecasts (Bierkens and Van Beek, 2009). The impact of groundwater on other near surface processes and thus the water budget defined by precipitation is also evident (Schaller and Fan, 2009). As appreciation for these interactive processes has grown, an increasing number of land surface models have been developed to account for the impact of groundwater on near surface processes (e.g., Koster et al., 2000a; Niu et al., 2007; Miguez-Macho et al., 2007; Yeh and Eltahir, 2005). Including groundwater in a land surface model enables a more complete simulation of the terrestrial water cycle, but it also subjects the modeled states to additional uncertainties associated with the added physical processes and parameters. For instance, due to lack of global-scale groundwater measurements, most models depend on calibration against other types of observations (such as stream flow data) to obtain the temporal variability and dynamic range of groundwater tables, which may not represent the interactions realistically, especially under extreme wet or dry conditions.

Precipitation data sets are a major source of uncertainty for land surface modeling, and their impacts on modeled states and fluxes may differ depending on seasons and climates (Fekete et al., 2004; Gottschalck et al., 2005). Great uncertainty also exists in model physics such as surface runoff algorithms which are often derived from empirical relationships (Koster et al., 2000a; Niu et al., 2005; Schaake et al., 1996). Stream flow is governed in varying degrees by topography, rainfall intensity, and soil wetness, making it a difficult process to simulate efficiently. Due to differences in model physics and parameter values, estimates by various land surface models exhibit large discrepancies even when models are run using identical forcing data (Mitchell et al., 2004). The combination of uncertainties in forcing, input parameters and model physics has led to dramatically different predictions for runoff and groundwater in response to future climate changes (Hoerling et al., 2009; Jackson et al., 2011; Poulin et al., 2011).

The ambiguity in model estimates also complicates drought monitoring, which increasingly relies on model estimated soil moisture due to the current lack of accurate global soil moisture measurements (Mo, 2008). While Koster et al. (2009) provided an optimistic assessment of the comparability of soil moisture estimates by various models, Mo (2008) indicated that although drought indices derived from different models show stronger correlation in the eastern US, their correlation is so low in the western US that model based drought indices cannot be used for drought monitoring. Drought monitoring is also complicated by the interaction between soil moisture and groundwater. Through numerical simulations, Peters et al. (2005) showed that groundwater can provide moisture to reduce the impact of short-term droughts, but due to its long recovery time groundwater will also act to lengthen and increase the frequency of droughts. The importance of groundwater for drought monitoring has been recognized (Svoboda et al., 2002; Rodell, 2012) and efforts have recently begun to combine information about groundwater variability as well as surface vegetation conditions with model estimated soil moisture to form comprehensive drought indices (http:// www.drought.unl.edu/MonitoringTools.aspx).

In order to capture the unique characteristics of TWS and reduce the uncertainty in model estimates, observations are needed to nudge model output towards reality. The GRACE satellite system detects temporal water storage changes in the entire vertical profile, including snow mass, surface water, vegetation, soil moisture and groundwater (Tapley et al., 2004). It is the only remote sensing platform that provides consistent monitoring of the Earth's terrestrial water storage, including groundwater. Recognizing the potential for GRACE data to improve the simulation of land surface processes, Zaitchik et al. (2008) developed an ensemble Kalman smoother (EnKS) to assimilate GRACE into the NASA Catchment model in the Mississippi basin, with promising results. The EnKS provides a systematic and dynamic way to disaggregate GRACE-derived TWS anomaly estimates into snow, soil moisture, and groundwater components, so that the simulation of each component of TWS can be positively influenced.

In this study, the EnKS and the Catchment model are applied in western and central Europe where climate and hydrological conditions differ significantly from the Mississippi area studied by Zaitchik et al. (2008) and the Mackenzie river basin studied by Forman et al. (2012). As droughts are common in Europe, the unique ability of GRACE TWS to detect droughts and its potential for drought monitoring are considered in some detail. The paper is organized as follows: Sections 2 and 3 describe the study domain, ground based validation data and the land surface model. Section 4 briefly outlines the EnKS method and filter parameters. Section 5 presents the model simulation results and comparisons with independent datasets. Comparisons of anomalies of GRACE TWS with those of MODIS NDVI are also presented. Section 6 concludes with a summary and discussion.

\section{Experiment site, GRACE and validation data}

Fig. 1 shows the simulation domain in western and central Europe. For GRACE data assimilation, hydrological watersheds were combined into nine major "basins" at the scale of GRACE derived TWS, to accommodate the effective spatial resolution of GRACE TWS, which is about $150,000 \mathrm{~km}^{2}$ at best (Rowlands et al., 2005; Swenson et al., 2006). Table 1 lists the area of these basins, ranging from 300,000 to $800,000 \mathrm{~km}^{2}$. Several islands and peninsulas such as Great Britain and Sweden/Norway were not included because GRACE TWS yielded much smaller dynamic ranges than model estimates, possibly due to the interference of ocean signals.

GRACE derived TWS anomalies used in this study were processed by University of Texas Center for Space Research (CSR, Release CSR_RL04) using a Gaussian filter with a $300 \mathrm{~km}$ smoothing radius to remove the stripes seen in the spherical harmonic coefficient fields (Swenson and Wahr, 2006). The monthly anomalies were obtained by removing the temporal mean of the gravity field (including the solid earth and the atmosphere) in 2003-2007 and converted to equivalent water heights. The resulting GRACE TWS anomalies, posted on a $1^{\circ}$ grid, were mapped to the nine major basins using area-weighted averaging, and, for the purpose of GRACE data assimilation, these values were converted to TWS by adding the 2003-2007 modeled mean TWS (unique for each basin) from an open loop (no data assimilation) integration of the model. Note that adding a constant value does not affect the temporal variability of GRACE TWS anomalies, including trends, correlation and ranks.

Fig. 1 also shows the locations of in situ measurements used for validating data assimilation results, including 18 stream flow stations along three major rivers (Danube, Elbe and Rhine) and 12 soil moisture sites from the Soil Moisture Observing System - Meteorological Automatic Network Integrated Application (SMOSMANIA, Calvet et al., 2007) project. The streamflow stations (station ids and drainage areas are given in Table 2) were chosen from Global Runoff Data Center (GRDC) for their length of records. Soil moisture measurements (started in 2007) are taken at 5, 10, 20 and $30 \mathrm{~cm}$ depths and every $30 \mathrm{~min}$ using impedance probes. Monthly 


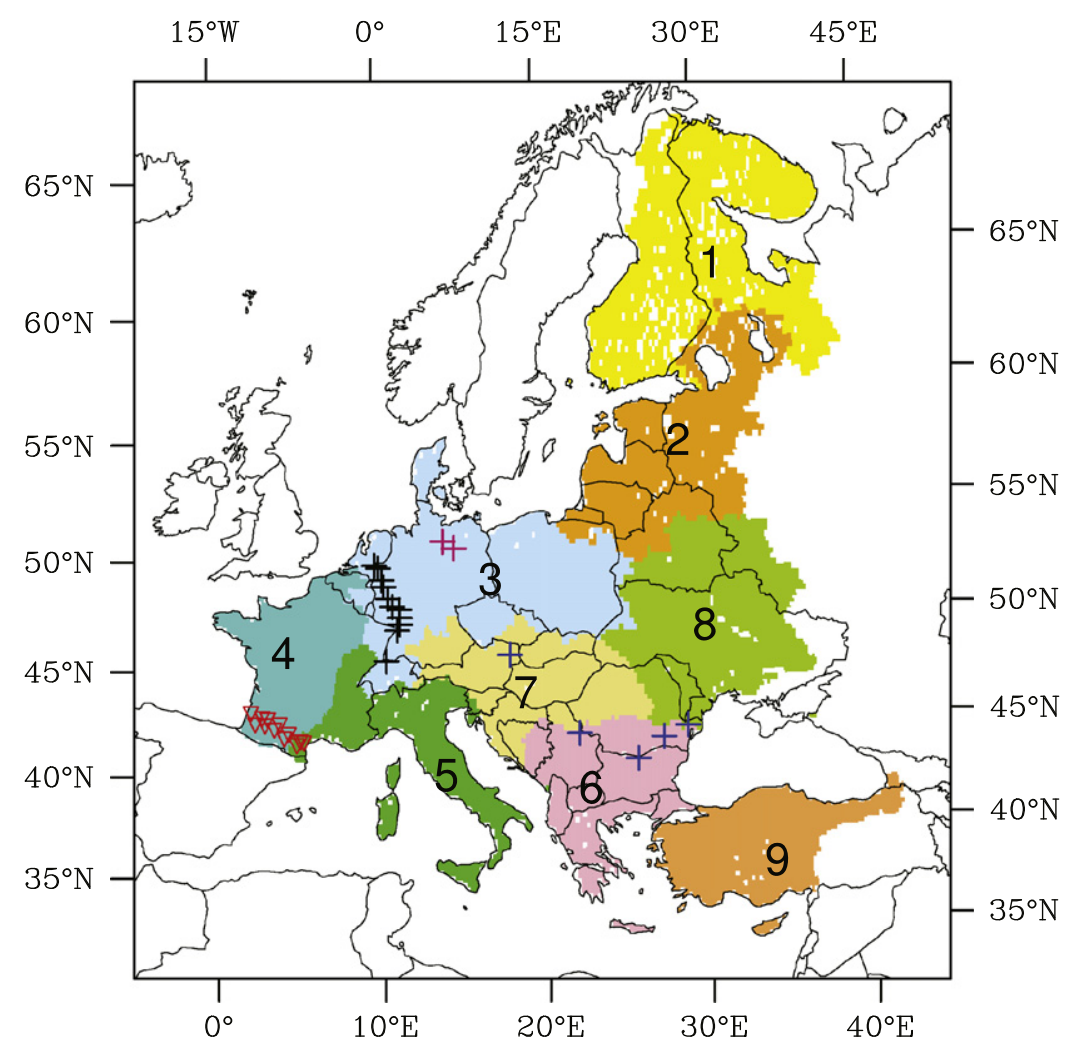

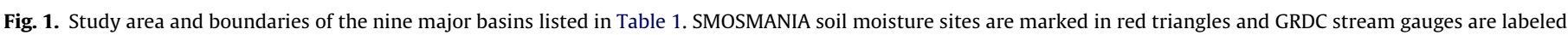

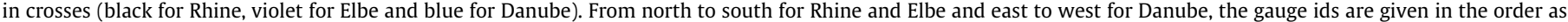
they appear in Table 2. (For interpretation of the references to color in this figure legend, the reader is referred to the web version of this article.)

Table 1

Major basins and their drainage areas.

\begin{tabular}{lll}
\hline Basin ID & Basin name & Area $\left(\mathrm{km}^{2}\right)$ \\
\hline 1 & Finland & 498,000 \\
2 & Vistula & 547,000 \\
3 & Rhine/Elbe/Oder & 797,000 \\
4 & Loire/Seine & 393,000 \\
5 & Rhone/Po & 319,000 \\
6 & Lower Danube & 503,000 \\
7 & Upper Danube & 490,000 \\
8 & Dnieper & 721,000 \\
9 & Turkey & 403,000 \\
\hline
\end{tabular}

averaged stream flow and root zone soil moisture (vertically integrated using the four layer measurements) were used to validate model simulation results.

\section{The Catchment model and forcing data}

The NASA Catchment model was developed for global scale coupled land/atmosphere modeling (Koster et al., 2000a). It simulates water and energy balances on catchment tiles, with some catchments split by a $1.0^{\circ} \times 1.25^{\circ}$ atmospheric grid. For the study domain, which consists of nearly 6000 tiles, the average tile size is around $1500 \mathrm{~km}^{2}$. To increase sub-grid heterogeneity, each catchment contains dynamically changing saturated, transpiring and wilting areas where different runoff and evapo-transpiration (ET) schemes are applied. The model contains three subsurface variables for water balance calculation: surface excess (sfEx) and root zone excess (rtzEx), representing the excessive soil moisture relative to the hydrostatic state for the top $2 \mathrm{~cm}$ and $100 \mathrm{~cm}$ of soils, respectively, and catchment deficit (catDef) defined as the amount of water $\left(\mathrm{kg} / \mathrm{m}^{2}\right.$, averaged over the catchment) needed to bring the catchment to saturation (assuming sfEx and rtzEx are zero). The dynamically changing runoff and evaporation zones are related to the three subsurface moisture variables through topography-related parameters; for example, the relationships used in the Alps are distinctly different from those used in flatter areas. Although groundwater is not explicitly simulated, its behavior, i.e., its two dimensional distribution and associated flow rates, is directly diagnosed from the catDef variable. The model also has three snow layers for modeling snow water equivalent (SWE) and snow depth. Modeled TWS can be calculated by subtracting catDef from and adding sfEx, rtzEx and SWE to the maximum available pore space of the catchment (determined from the bedrock depth and porosity). Lakes and reservoirs are not directly included in simulated TWS because, over large scales at mid-latitudes, they only constitute a very small fraction of observed TWS variability (Rodell and Famiglietti, 2001). The impact of GRACE data assimilation on runoff is exerted through its relationship with modeled states: sfEx, rtzEx, catDef and SWE.

Forcing fields were provided by the Global Land Data Assimilation System (GLDAS, Rodell et al., 2004). They are based on meteorological fields (temperature, humidity, wind speed and pressure) obtained from the NASA Global Modeling and Assimilation Office GEOS data assimilation system (Bloom et al., 2005), radiation fields from the US Air Force Weather Agency, and precipitation prepared by spatially and temporally downscaling the $2.5^{\circ} \times 2.5^{\circ}, 5$-day NOAA Climate Prediction Center (CPC) Merged Analysis of Precipitation (CMAP; Xie and Arkin, 1997). This GLDAS/CMAP forcing data set, which has been used in previous data assimilation experiments (Reichle et al., 2007; Zaitchik et al., 2008), has a 3 h temporal interval and a $2^{\circ} \times 2.5^{\circ}$ spatial resolution.

A few adjustments and corrections were made in this study regarding the Catchment model and forcing fields. Zaitchik et al. (2008) found that Catchment sometimes does not provide a large 
Table 2

GRDC stations, drainage areas, record lengths and root mean square errors (RMSE, $\mathrm{mm} / \mathrm{d}$ ) of monthly simulated runoff.

\begin{tabular}{|c|c|c|c|c|c|}
\hline \multirow[t]{2}{*}{ Station ID } & \multirow[t]{2}{*}{ GRDC number } & \multirow[t]{2}{*}{ Drainage area $\left(\mathrm{km}^{2}\right)$} & \multirow[t]{2}{*}{ Record length (months) } & \multicolumn{2}{|c|}{$\operatorname{RMSE}(\mathrm{mm} / \mathrm{d})$} \\
\hline & & & & $\mathrm{OL}$ & DA \\
\hline \multicolumn{6}{|l|}{ Rhine } \\
\hline $\mathrm{R} 1$ & 6435060 & 160,800 & 65 & 0.45 & 0.42 \\
\hline $\mathrm{R} 2$ & 6335020 & 159,300 & 77 & 0.47 & 0.45 \\
\hline R3 & 6335050 & 147,600 & 77 & 0.44 & 0.42 \\
\hline $\mathrm{R} 4$ & 6335060 & 144,200 & 77 & 0.47 & 0.45 \\
\hline R5 & 6335070 & 139,500 & 77 & 0.46 & 0.44 \\
\hline R6 & 6335100 & 103,500 & 77 & 0.56 & 0.55 \\
\hline R7 & 6335150 & 98,200 & 77 & 0.55 & 0.53 \\
\hline R8 & 6335180 & 68,800 & 77 & 0.73 & 0.72 \\
\hline R9 & 6335170 & 53,100 & 77 & 1.14 & 1.14 \\
\hline R10 & 6335200 & 50,200 & 77 & 0.99 & 0.99 \\
\hline R11 & 6335400 & 34,600 & 77 & 1.49 & 1.48 \\
\hline \multicolumn{6}{|l|}{ Elbe } \\
\hline E1 & 6340110 & 131,900 & 77 & 0.17 & 0.14 \\
\hline E2 & 6340150 & 123,500 & 77 & 0.17 & 0.15 \\
\hline \multicolumn{6}{|l|}{ Danube } \\
\hline D1 & 6742900 & 807,000 & 77 & 0.43 & 0.39 \\
\hline $\mathrm{D} 2$ & 6742800 & 709,100 & 84 & 0.18 & 0.18 \\
\hline D3 & 6742500 & 658,400 & 84 & 0.45 & 0.41 \\
\hline D4 & 6742201 & 570,900 & 77 & 0.44 & 0.38 \\
\hline D5 & 6242501 & 101,500 & 53 & 0.98 & 0.92 \\
\hline
\end{tabular}

enough dynamic range to match that of GRACE TWS. The same situation was observed in this study region as well. To mitigate this deficiency, the bedrock depth used for the model was uniformly increased by $2 \mathrm{~m}$, which increased the dynamic range of catDef. Furthermore, the resistance to bare soil evaporation was increased, in line with recent findings associated with modeling the carbon cycle (not shown). To partially compensate for the increase in bedrock depth, a lower value of the decay factor for saturated conductivity (1.0 rather than the default 2.17) was used for the base flow calculation (Ducharne et al., 2000). Longwave and shortwave radiation fields were further bias corrected based on NASA/ GEWEX Surface Radiation Budget (SRB, Release-3.0) data by matching their spatial (for entire simulation area) and temporal averaged means with those of SRB. The goal of these adjustments and corrections, used in both the open loop and data assimilation simulations discussed below, was to achieve more reasonable estimates of fluxes (ET and runoff) in the open loop case. Indeed, by improving the open loop simulation, we set the bar higher for improvement through the assimilation of GRACE data, with the goal of more clearly isolating the unique benefit of these data. Undoubtedly other combinations of parameter changes (not tested comprehensively here) could lead to similar benefit.

Simulations (in 20-min time steps) were carried out from $\mathrm{Au}-$ gust 2002 to July 2009, which was the available GRACE data period at the start of this study. Since previous forcing data were not available, the model was first run through 2002-2009 and then spun up for 10 years using the forcing fields from 2002. A different initial condition, based on averaged model states from 2002 to 2009 on January 1, which yielded wetter soil moisture conditions than the one mentioned above, was also tested and the results (including runoff and soil moisture evaluations) were very similar to those presented here.

\section{GRACE data assimilation method}

Because of the nature of GRACE TWS, i.e., monthly averaged values, a smoothing filter, which is often used to assimilate noninstantaneous observations, is more appropriate than a standard filter for assimilating GRACE TWS. Zaitchik et al. (2008) presents a detailed description of the ensemble Kalman Smoother (EnKS) developed specifically for assimilating GRACE TWS into the Catchment model, and additional information is provided by Forman et al. (2012). A brief outline of this assimilation method is presented here. Like an ensemble Kalman filter (EnKF), the EnKS consists of two steps: forecast and update. In the forecast step, the ensemble of the model runs forward in time with perturbations added to the states and forcing fields:

$X_{T^{-}}^{i}=M\left(X_{(T-1)^{+}}^{i}, F^{i}, G\right)$

where $M$ is the model; $F$ represents all the forcing fields and $G$ represents all the static parameters; $T$ is the time; superscripts (-) and $(+)$ refer to results for the forecast and update, respectively; $X$ is the vector containing updated states (rtzEx, catDef and SWE) for each catchment tile, and the superscript $i$ indicates the $i$ th member of the ensemble. srfEx was not updated in the EnKS because of its very weak correlation with monthly TWS but was included in model simulated TWS for accuracy. Based on Eq. (1), the ensemble update equation can be written as:

$X_{T^{+}}^{i}=X_{T^{-}}^{i}+K_{T}\left(\underline{Y}_{T}-H\left(\underline{X}_{T^{-}}^{i}\right)\right)$

where $K$ is the ensemble gain matrix; $Y$ represents observations (GRACE TWS) and $H$ is the observation operator that converts predicted states to the observation.

The underscores in Eq. (2) indicate monthly TWS (observed or simulated) averaged for each major basin because the EnKS used here assimilates temporally integrated observations. To accommodate the monthly averaged nature of GRACE TWS, the EnKS collects Catchment model predictions of TWS on a first pass through each simulated month (three collections per month, to mimic GRACE overpass characteristics), calculates the update at the end of the month, and then iterates through the month a second time, uniformly (for each state) applying increments to each daily value of model states for each ensemble member. Thus, $X$ (without the underscore) in Eq. (2) represents daily estimates of model states on each catchment tile in month $T$.

All perturbation parameters and schemes were the same as those in Zaitchik et al. (2008) and Reichle et al. (2007), except that an observation (GRACE) error of $15 \mathrm{~mm}$ was used here, which is the average of the two GRACE errors $(10 \mathrm{~mm}$ and $20 \mathrm{~mm}$ ) tested by Zaitchik et al. (2008). The combined impact of these model/forcing and observation errors directly influences the value of the ensemble gain matrix, which in turn determines the update each 
modeled state receives based on the difference between the observed and model TWS.

\section{Results}

Two model integrations were performed from August 2002 to July 2009: the open loop (OL) representing the model-only performance and the GRACE data assimilation (DA) using the EnKS outlined above. For consistency, twenty ensemble members, generated using the same perturbation parameters, were employed for each simulation.

\subsection{TWS and the disaggregation of GRACE data}

Fig. 2 presents the time series of daily simulated TWS and monthly GRACE TWS for the nine major basins. A baseline reference value (the minimum TWS in each basin) was subtracted from each of the three time series (OL, DA and GRACE) to facilitate
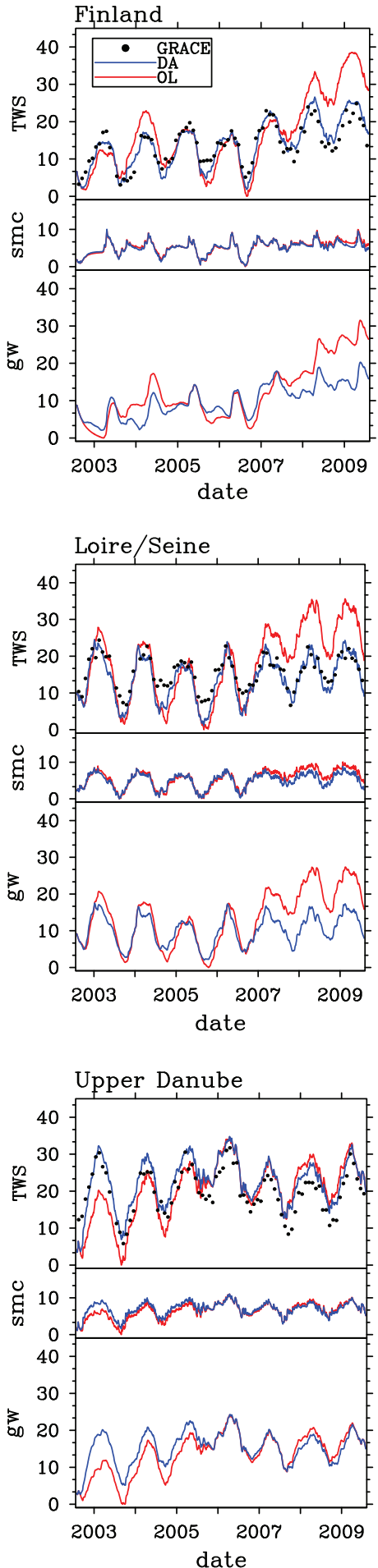
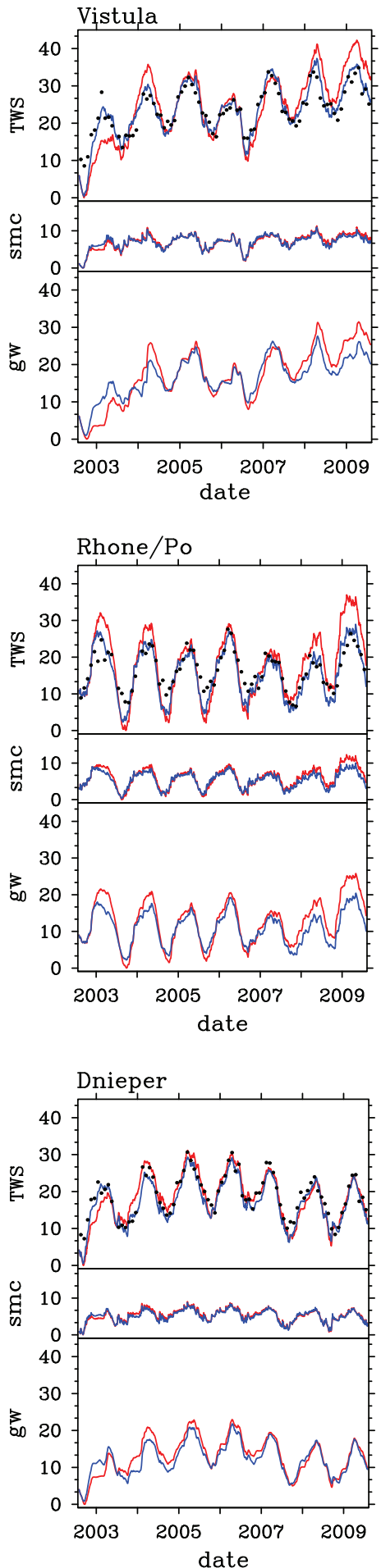
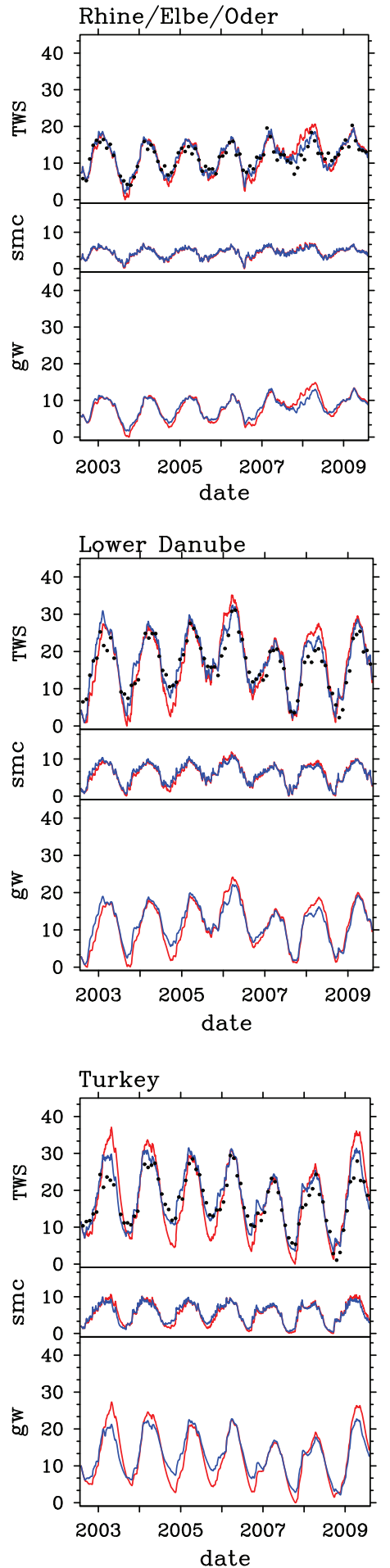

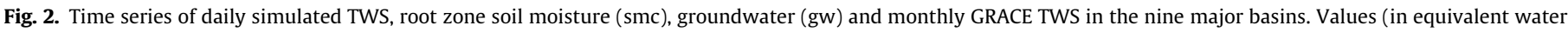
height, $\mathrm{cm}$ ) were obtained by subtracting the minimum value of each field in each basin from their estimates. 

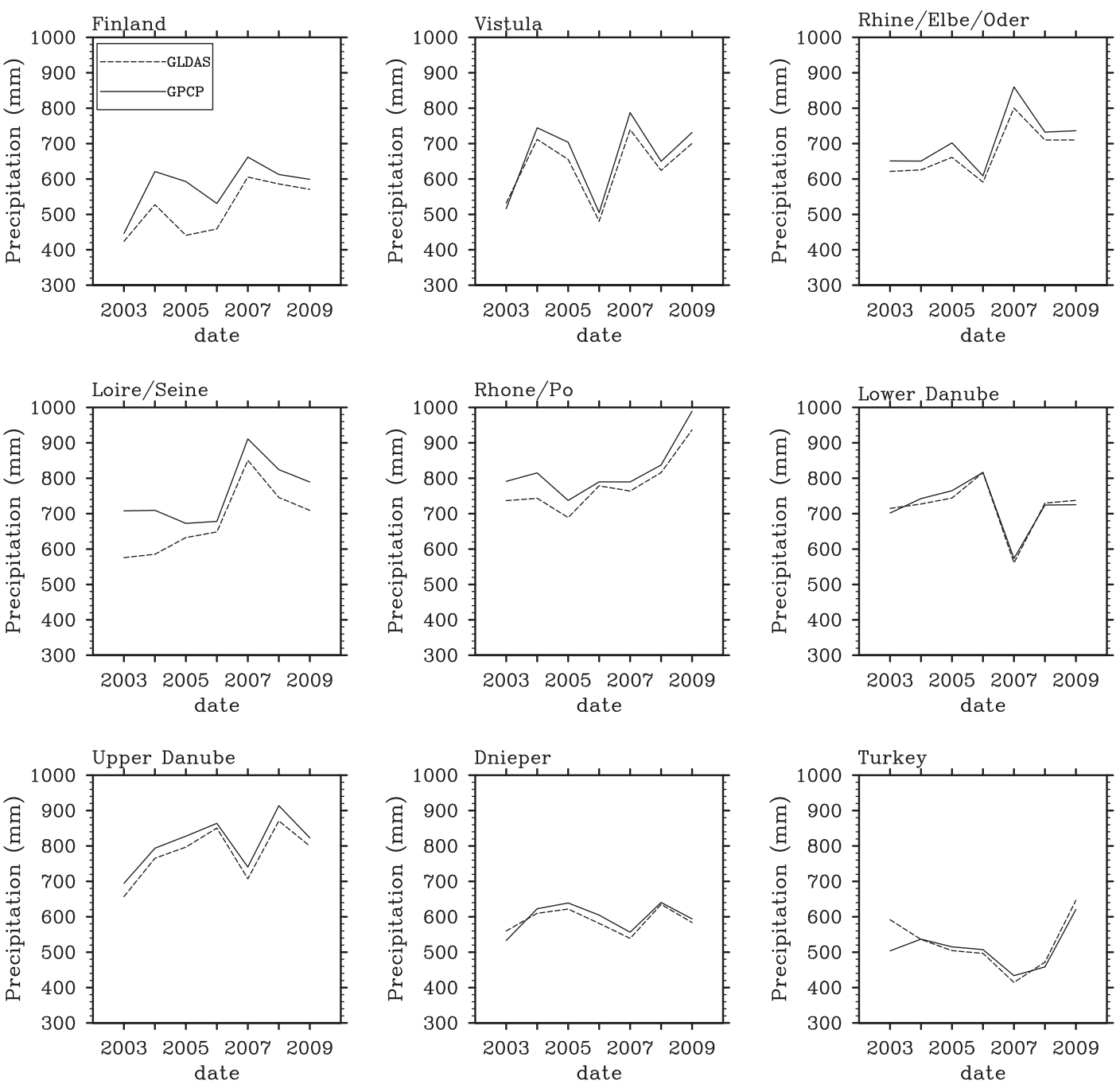

Fig. 3. Comparisons of annual GLDAS/CMAP and GPCP precipitation in the nine basins.

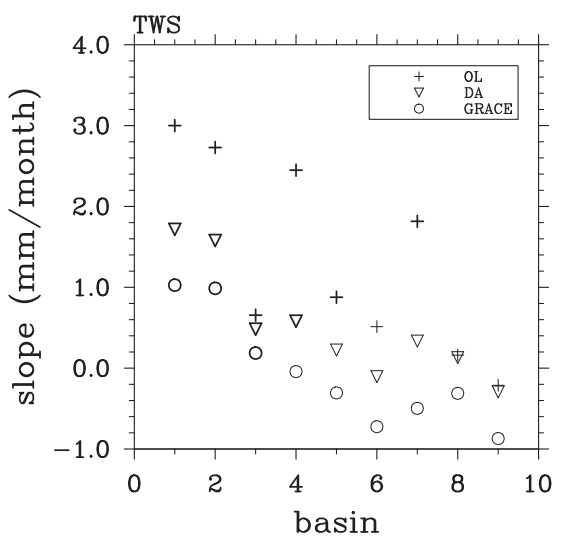

Fig. 4. Slopes of trend for monthly TWS in the nine major basins. Trends with a 0.1 significance level are marked with bold symbols.

comparison with other basins and with other components of TWS. The open loop run generally captured the seasonal variability and dynamic range of GRACE TWS. OL differs from GRACE mostly in interannual variability, especially in Finland, Loire/Seine and Rhone/Po where OL exhibits a marked increase in TWS in the later modeling period. While data assimilation checked that increase effectively, consistent with GRACE TWS, it failed to reduce the

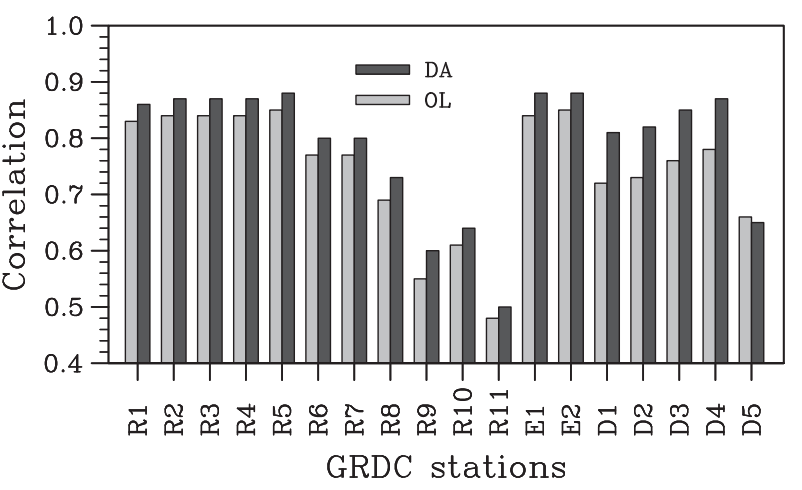

Fig. 5. Correlations of monthly simulated runoff with GRDC stream flow. All improvements by DA exceed the 0.05 significance level. Station ids are given in Table 2.

simulated TWS to the levels observed by GRACE in the Upper Danube in 2007 and 2008. This failure was possibly caused by negligible ensemble spread during dry conditions due to a lack of precipitation to perturb and the fact that direct perturbations to sfEx and catDef are small. Increasing the direct perturbations may enable TWS to go lower, but it may also lead to ensemble bias. Nevertheless, in most cases EnKS was effective in nudging the 

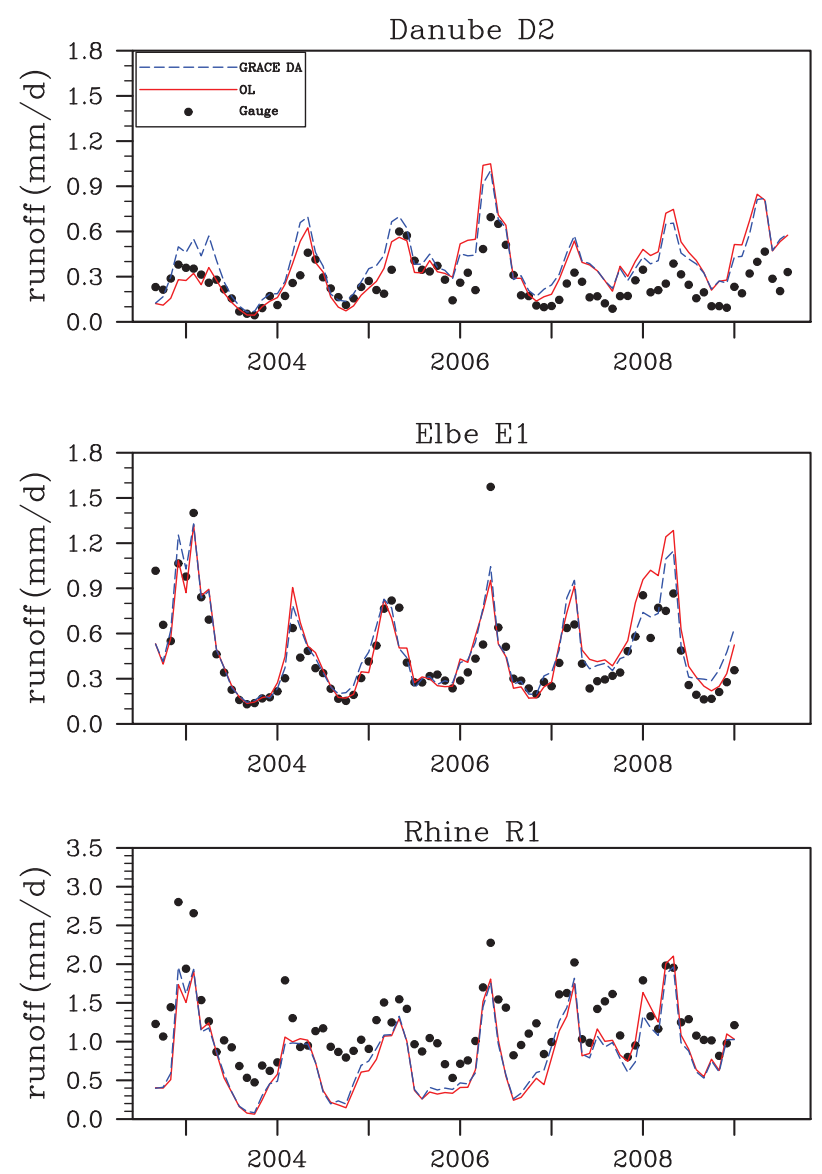

Fig. 6. Monthly time series of estimated runoff in comparison with GRDC gauge data at selected watersheds.

simulated TWS toward GRACE TWS. Fig. 2 also demonstrates the effect of temporal downscaling of monthly GRACE TWS into daily values by the EnKS. As expected, the temporal variability (daily) of OL is preserved in the DA TWS time series.

To investigate the cause of the significant increase in OL TWS seen in the Finland, Vistula, Loire/Seine, and Rhone/Po basins, which was not observed as dramatically in the GRACE TWS (Fig. 2), GLDAS/CMAP precipitation was compared with $1^{\circ} \times 1^{\circ}$ Global Precipitation Climatology Project (GPCP) precipitation data

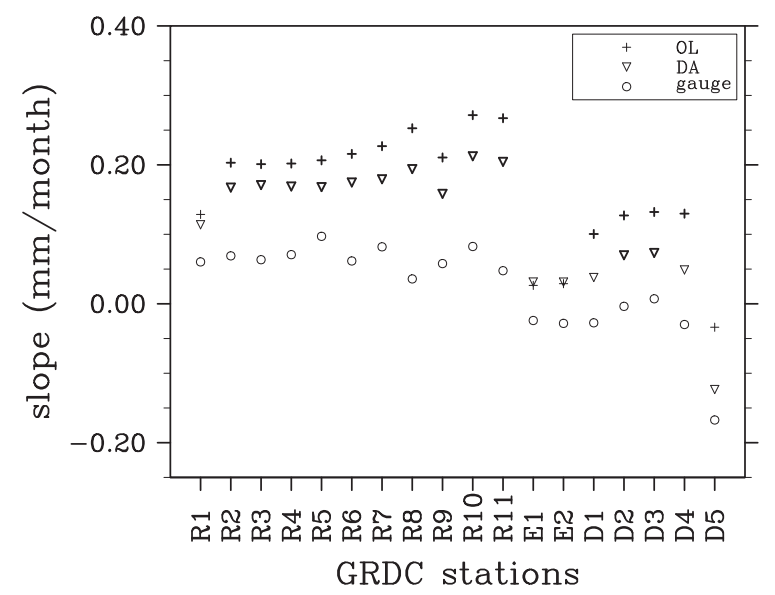

Fig. 7. Slopes of trend for monthly runoff at GRDC stations. Trends with a 0.1 significance level are marked with bold symbols.
Table 3

Correlations and root mean square errors (RMSE) of monthly simulated root zone soil moisture at SMOSMANIA sites. Except for the URG site, the OL and DA correlation values are not significantly different at the 0.10 significance level.

\begin{tabular}{|c|c|c|c|c|c|}
\hline \multirow[t]{2}{*}{ Site } & \multirow[t]{2}{*}{ Record length (months) } & \multicolumn{2}{|c|}{ Correlation } & \multicolumn{2}{|c|}{ RMSE } \\
\hline & & OL & DA & $\mathrm{OL}$ & DA \\
\hline CDM & 31 & 0.75 & 0.67 & 0.06 & 0.07 \\
\hline CRD & 29 & 0.71 & 0.76 & 0.14 & 0.12 \\
\hline LHS & 26 & 0.62 & 0.51 & 0.07 & 0.10 \\
\hline LZC & 28 & 0.68 & 0.67 & 0.23 & 0.22 \\
\hline MNT & 29 & 0.90 & 0.90 & 0.06 & 0.06 \\
\hline MTM & 22 & 0.67 & 0.66 & 0.06 & 0.06 \\
\hline NBN & 28 & 0.44 & 0.36 & 0.17 & 0.16 \\
\hline PRG & 25 & 0.80 & 0.77 & 0.04 & 0.05 \\
\hline SBR & 31 & 0.83 & 0.83 & 0.03 & 0.03 \\
\hline SFL & 31 & 0.67 & 0.72 & 0.10 & 0.09 \\
\hline SVN & 28 & 0.65 & 0.56 & 0.07 & 0.06 \\
\hline URG & 31 & 0.81 & 0.75 & 0.08 & 0.10 \\
\hline Average & 31 & 0.84 & 0.84 & 0.06 & 0.05 \\
\hline
\end{tabular}

(Adler et al., 2003) mapped to the major basins following the same approach as that for GRACE. Fig. 3 shows the comparison of annual (from August to July) precipitation totals in each basin. In general, GLDAS/CMAP has a negative bias against GPCP in all basins except Turkey. CMAP's negative bias relative to other precipitation products stems from the fact that it does not correct for gauge undercatch (e.g., Yin et al., 2004). More importantly, the annual variations of GPCP and GLDAS/CMAP precipitation are well correlated, and both products indicate that precipitation in the four basins named above increased towards the end of the simulation period. Given that GRACE TWS also increased in those basins but to a lesser extent, we infer that either: (i) the model should have retained less water in the land and increased evapotranspiration (ET) and/or runoff instead or (ii) the precipitation and GRACE datasets are inconsistent, due to errors in one or both.

The rate of long-term TWS changes can be more clearly illustrated using the slope of monthly TWS calculated using Sen's method (Helsel and Hirsch, 1992; Sen, 1968) as shown in Fig. 4. Slopes with a 0.1 significance level were identified using the Mann-Kendal test (Helsel and Hirsch, 1992) and marked in bold symbols. These two methods have been widely used in analyzing trends in hydro-meteorological data sets (Mishra and Cherkauer, 2010; Lettenmaier et al., 1994; Yue and Wang, 2002). Fig. 4 shows that the slope of TWS (modeled or observed) is generally smaller in the southern part of the region, which resembles the increasing rate of annual precipitation in each basin (Fig. 3), suggesting the strong correlation of TWS with long-term precipitation. OL TWS generally exhibits larger rates of increase than GRACE TWS, especially in Finland, Vistula, Loire/Seine and Upper Danube, where larger increasing rates of precipitation were observed in the later modeling period (Fig. 3 ).

To illustrate the vertical disaggregation of GRACE TWS, daily values of root zone soil moisture and groundwater (with a minimum value subtracted from each field) are also plotted in Fig. 2. Both fields were converted to equivalent water heights $(\mathrm{cm})$ so their quantities are comparable to TWS. Updates in TWS were distributed to soil moisture and groundwater with more of each update going to groundwater due to its stronger correlation with the catDef variable and TWS. It is easy to see that the significant increase of TWS in basins like Finland in the OL simulation largely came from groundwater, as opposed to soil moisture which does not show large increasing trends in any basin. This may reflect the need for improvement in the model formulations of recharge and/or baseflow or the accumulation of bias errors in the forcing data. Some noticeable trend changes in soil moisture caused by GRACE data assimilation are observed in Loire/Seine, Rhone/Po 

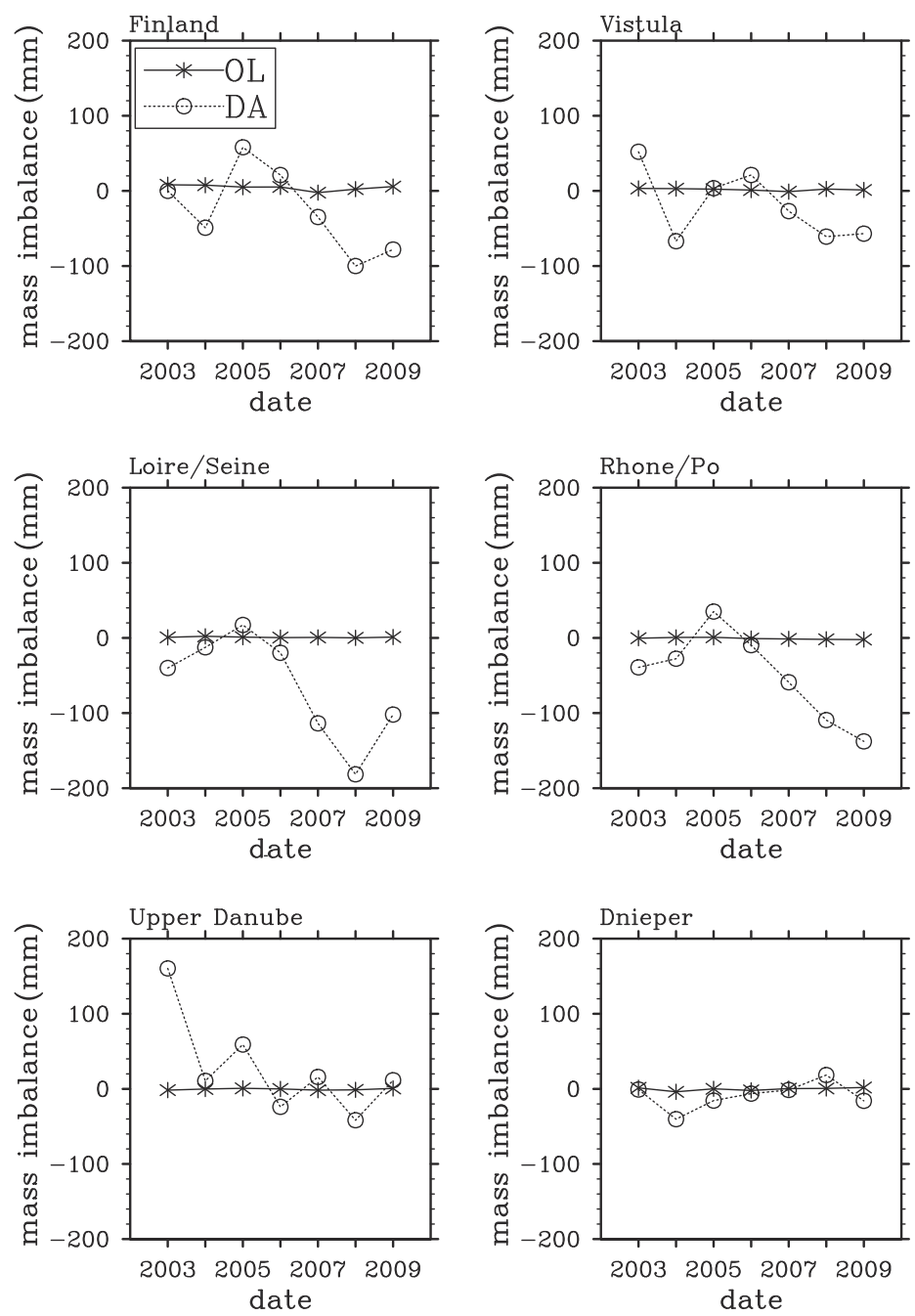
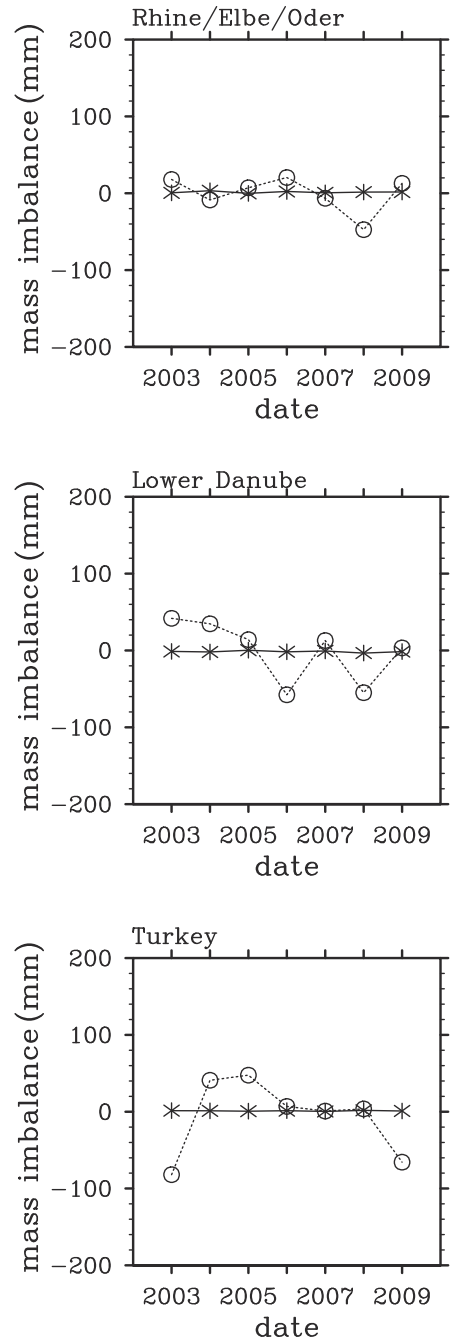

Fig. 8. Annual mass imbalance (simulated water budget minus precipitation) for OL and DA in the nine major basins.

and Upper Danube, which should have an impact on agricultural drought monitoring.

SWE estimates are not included in Fig. 2 because they are insignificant in most basins, except in Finland and Vistula where the sum of soil moisture and groundwater time series differs from TWS time series. The presence of snow weakened the correlation of soil moisture with TWS in winter, which can be seen in Finland where the update of soil moisture is much smaller than that in Loire/Seine and Rhone/Po during 2008-2009, despite similar or even larger updates in TWS. Due to limited subsurface states in Catchment, further disaggregation of TWS into multiple layers in the unsaturated zone (from the surface to the groundwater table) was not achieved. Nevertheless, the ability of the EnKS in conjunction with a high resolution model and forcing data to downscale and disaggregate GRACE TWS is evident in Fig. 2.

Modeled groundwater in Finland shows a weaker second peak in the fall which coincides with increased precipitation and decreased ET and was also observed in other numerical studies in the area (Okkonen and Kløve, 2011). In OL, the second peak in the fall became higher than the spring peak in 2007-2009. GRACE data assimilation significantly lowered the second peak during those years.

Note that the groundwater in this graph was obtained by simply subtracting SWE and root zone soil moisture from TWS, i.e., it includes soil moisture in the intermediate zone between the bottom of the root zone (defined here as the top $1 \mathrm{~m}$ of the soil) and the water table. The exact change in groundwater resources was not calculated because estimates of the specific yield of the aquifers were unavailable.

\subsection{Evaluation of stream flow and soil moisture with independent observations}

The availability of stream flow data and the fact that stream flow is a product of upland surface and subsurface runoff over a large area make gauged stream flow data among the most utilized data set for evaluating model performances. For the same reason, stream flow measurements were used here not only to evaluate the impact of GRACE data assimilation on runoff but also to provide an overall assessment of the EnKS. Fig. 5 shows the correlation of monthly simulated runoff with GRDC gauge data. Since Catchment does not have a routing scheme, the simulated stream flow is simply a spatial aggregation of tile-space (individual land element) runoff over the drainage area. This is adequate for monthly statistics, especially in smaller basins where the runoff response time is less than a month. GRACE data assimilation improved the correlation in all watersheds but one (D5), with more improvement (the largest improvement is $17 \%$ at D2 and the smallest improvement is $5 \%$ at R1) observed in larger basins along the Danube. Improvements in watersheds such as R6-R11, E1 and E2 (Table 2) with drainage areas smaller than their corresponding major basins 

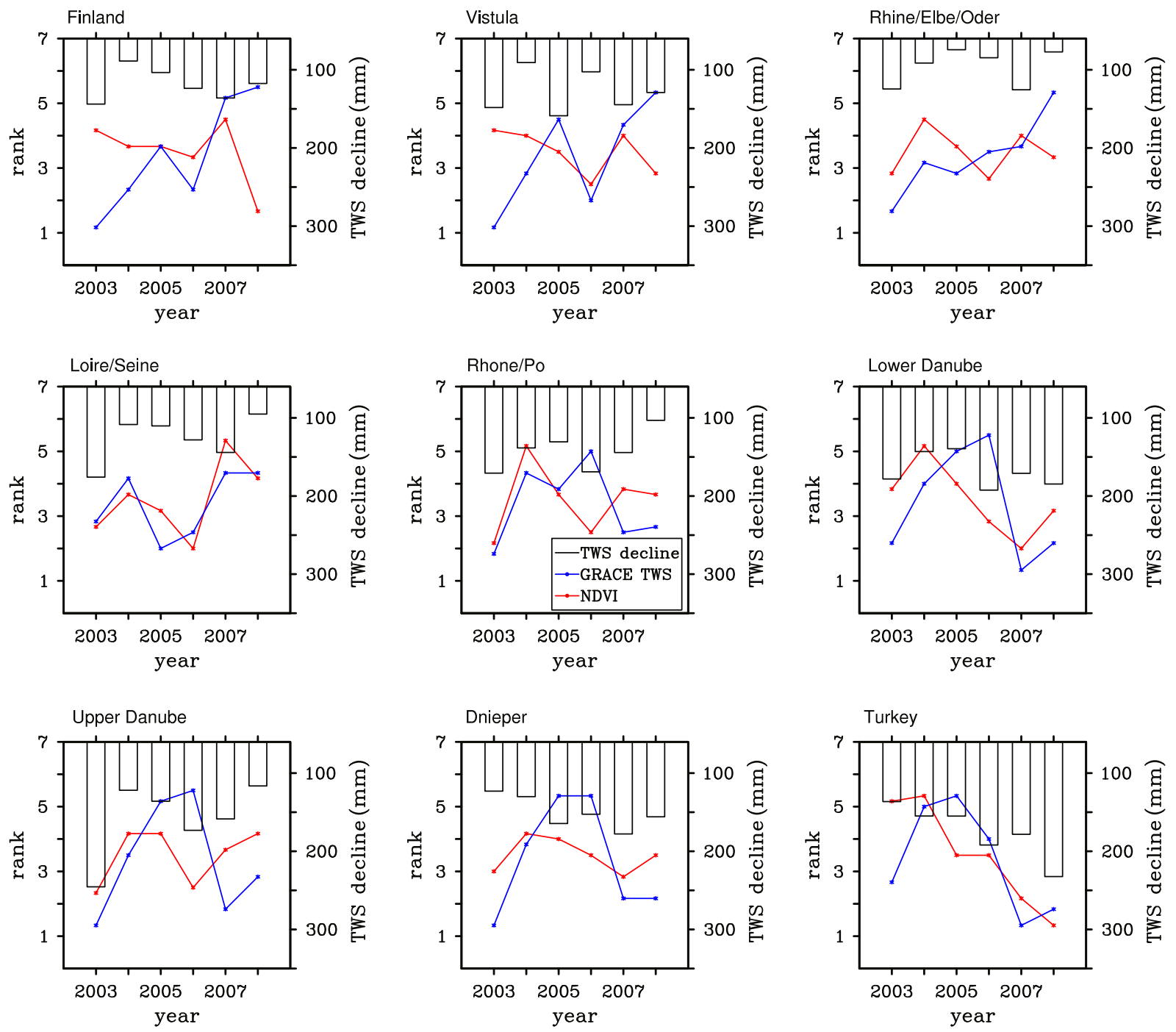

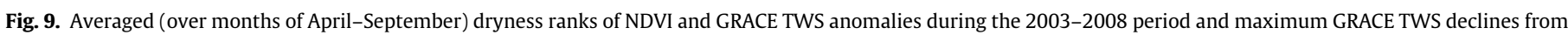
spring to fall in each year.

(the scale at which GRACE TWS was generated) indicate that assimilation of GRACE TWS can influence simulation of land surface processes at sub-observation scale. The improvements shown in Fig. 5 by DA all exceeded the 0.05 significance level based on the William-Hotelling $t$-test (Steiger, 1980; Van Sickle, 2005). Table 2 also lists the root mean square errors (RMSEs) of runoff estimates against GRDC data. Data assimilation reduced RMSE in all but one basin. It should be pointed out that the stream flow metrics at different stations along the same river are not independent.

Improvements in runoff correlations are attributed to the close relationship between base flow and catDef, which is the model state most affected by assimilation of GRACE TWS. To illustrate this, Fig. 6 shows the time series of simulated runoff in comparison with GRDC measurements at one gauge location from each of the three rivers. In the Danube (D2), DA significantly increased the runoff in the earlier period in accordance with changes in TWS, which helped to improve the overall correlation by lowering the increasing trend of runoff. The impact of GRACE DA on runoff estimates in E1 and R1 is less significant, due to smaller updates of TWS in the Rhine/ Elbe/Oder basin (Fig. 2). Fig. 7 shows the trend of runoff by OL, DA and GRDC gauge data in all GRDC basins. Similar to TWS, model estimates (OL) show larger trends than observed runoff with significant trends detected for most basins while observed runoff shows no significant trend in any basin. DA reduced trends in all basins, but did not change the significance level of most trends.

An important role of the EnKS is to disaggregate GRACE so that each TWS component can be nudged towards its true state. To evaluate the vertical disaggregation, correlation coefficients and RMSE of monthly root zone soil moisture estimated by OL and DA were calculated against in situ measurements from the SMOSMANIA sites and are given in Table 3. The statistics were calculated using in situ point data and model estimates at the tile containing the station. GRACE data assimilation generally did not have a significant impact on monthly correlations of soil moisture as the correlation of DA is not different from OL at the 0.10 significance level, except at site URG. The coarse spatial scales of the model and the GRACE data complicate comparisons with in situ soil moisture measurements. To alleviate the horizontal scale mismatch and obtain an overall impact on the entire SMOSMANIA area (about $4000 \mathrm{~km}^{2}$ ), the area averaged statistics for OL and DA were also calculated against the averaged in situ measurements and are given in Table 3 (last row). The area average metric shows that GRACE data assimilation did not change the correlation of the averaged soil moisture time series in the sampling area but reduced RMSE slightly. The shorter SMOSMANIA data period (31 months) makes these statistics less conclusive because the confidence intervals are very large. 

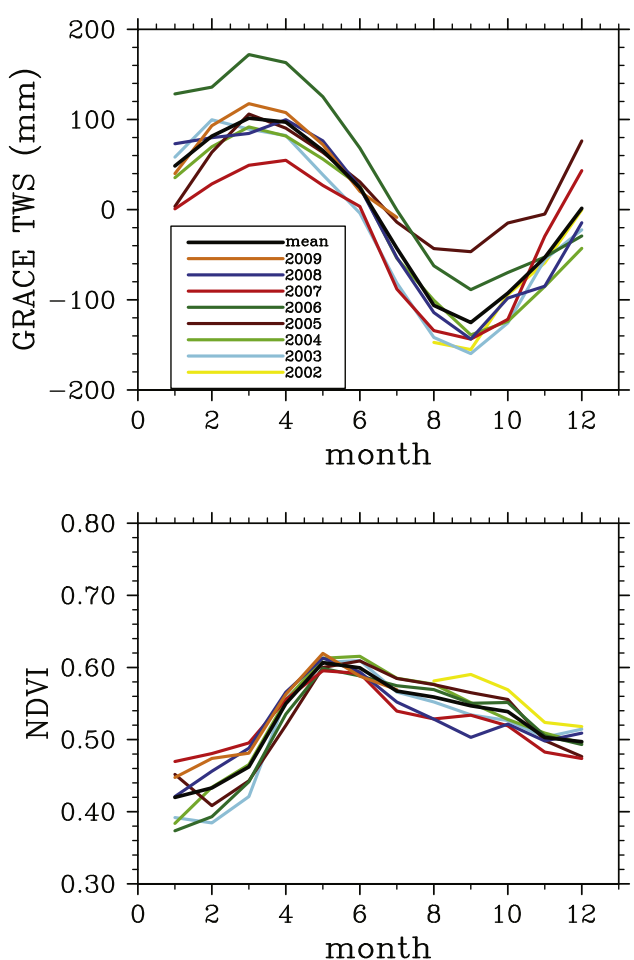

Fig. 10. Seasonal cycles of GRACE TWS anomalies and NDVI in Lower Danube.

\subsection{Water budget}

As hypothesized in Section 5.1, elevated OL estimates of TWS in Finland and Loire/Seine in the later modeling period were likely caused by either an underestimation of runoff and/or ET when precipitation rates increased or by improper increase in the precipitation rates themselves (assuming GRACE data are accurate). When GRACE data assimilation reduced TWS in these basins, it also decreased ET and runoff estimates because of the impact of moisture availability on these processes. Consequently, the water budget of the GRACE DA simulation during the GRACE data assimilation only closes if non-zero assimilation increments are included. Fig. 8 features the annual (August-July) mass imbalance, defined as the simulated water budget (sum of total fluxes and net change in TWS) minus precipitation, of OL and DA. As expected, OL has nearly zero mass imbalances throughout the entire period and in all basins. In contrast, GRACE data assimilation disrupted the water budget, more so in Finland, Vistula, Loire/Seine and Rhone/Po, despite improving the simulation of TWS (again assuming GRACE data are accurate). Since GLDAS/CMAP precipitation generally has a negative bias against GPCP (Fig. 3), positive imbalances (i.e., larger ET and runoff) might be preferable to the negative ones produced by GRACE data assimilation in this case. Unintended impacts of data assimilation on the water budget are always a danger, demanding the development of creative new assimilation techniques (e.g., Li et al., 2012; Pan and Wood, 2006; Zaitchik and Rodell, 2009).

\subsection{Drought analysis}

Droughts are common in Europe, and several episodes of severe droughts, including the 2003 drought (associated with the 2003 European heat wave, Rebetez et al., 2006; Zaitchik et al., 2006) that spread across western and central Europe and the 2007/2008 droughts that affected southern and southwestern Europe (SOER Synthesis, 2010), were detected by GRACE TWS (Fig. 2). Because droughts can be defined in a variety of ways depending on what indicators are taken into account, it can be instructive to compare a new drought observation with a more common indicator. Here we compare GRACE TWS anomalies with monthly Normalized Difference Vegetation Index (NDVI) as recorded by the Moderate Resolution Imaging Spectroradiometer (MODIS) instrument on NASA's Terra satellite. NDVI is strongly correlated with green biomass (Tucker, 1979), and is often used in satellite based drought-monitoring (e.g., Brown et al., 2008). Basin averaged NDVI was derived by averaging the Level-3 $0.05^{\circ}$ MODIS NDVI monthly product (lpdaac.usgs.gov) across the same basins that were used to extract GRACE TWS.

Fig. 9 shows the dryness ranks of monthly NDVI and GRACE TWS anomalies, averaged over the summer season (April-September), for the 2003-2008 period (2002 and 2009 were excluded due to their incomplete summer seasons). To give equal weight to all ranks, the ranks in Fig. 9 were obtained by first ranking each data set for each month and then averaging the ranks over the summer months. GRACE identified 2003 as the driest summer in all basins except Loire/Seine, Lower Danube and Turkey, while NDVI only shows 2003 as the most severe drought in Rhone/Po, Upper Danube and Dnieper and as a modest drought in Rhine/Elbe/Oder and Loire/Seine. The 2007/2008 droughts along the south and southwestern region (in Rhone/Po, Lower/Upper Danube, Dnieper and Turkey) were detected by both types of observations. The largest discrepancies between the two sources are in Finland and Vistula where, despite the increasing trend in precipitation (Fig. 3), NDVI shows decreasing trends. This is probably due to the fact that vegetation growth in high latitude and high elevation regions is limited by energy availability, not by water availability (Karnieli et al., 2010).

Note that GRACE characterized the 2003 drought in Loire/Seine as less severe than the 2005 drought (SOER Synthesis, 2010). According to GRACE, the land was very wet in early 2003 (Fig. 2), and as a result dry meteorological conditions took longer to severely impact total TWS. In this situation, the effect of drought is less evident in the TWS anomaly than it is in the maximum decline of GRACE TWS from its early spring peak to the lowest value in the fall, which roughly measures the amount of water lost in the warm season. As seen in Fig. 9, Loire/Seine and Upper Danube, which were at or near the center of the 2003 heat wave, experienced the most significant water loss in 2003. This is one of the advantages of using a physical-based variable for drought monitoring because drought conditions can be evaluated using a physical quantity other than anomalies.

The reason that we only compared the dryness rank of GRACE and NDVI during the warm season in Fig. 9 is that NDVI is insensitive to water shortage when vegetation is senescent or when coverage is low (Karnieli et al., 2010). This can be seen in Fig. 10 where the seasonal cycles of GRACE anomalies and NDVI in the Lower Danube basin are presented. GRACE indicated moisture stress in 2007 very consistently over all seasons, in contrast with NDVI which indicated vegetation stress only after June. This quality, true in most areas (Rodell, 2012), is important both for drought monitoring and for early detection of drought onset and therefore makes GRACE a useful complement to high-resolution NDVI-based measures of drought, especially in regions with low vegetation cover or where water is not a limiting factor for vegetation growth.

Figs. 9 and 10 show the dryness ranks based on GRACE TWS alone. To demonstrate the potential value of integrating GRACE TWS and other data with a land surface model for drought monitoring, Fig. 11 plots the dryness ranks (among 2002-2009) of OL and DA estimates of root zone soil moisture (upper panels), which is of particular interest for monitoring agricultural droughts, and TWS (lower panels), which mainly reflects water depletion in the deeper subsurface, for November 2007. GRACE DA intensified the drought condition in Loire/Seine and Upper Danube relative to the 

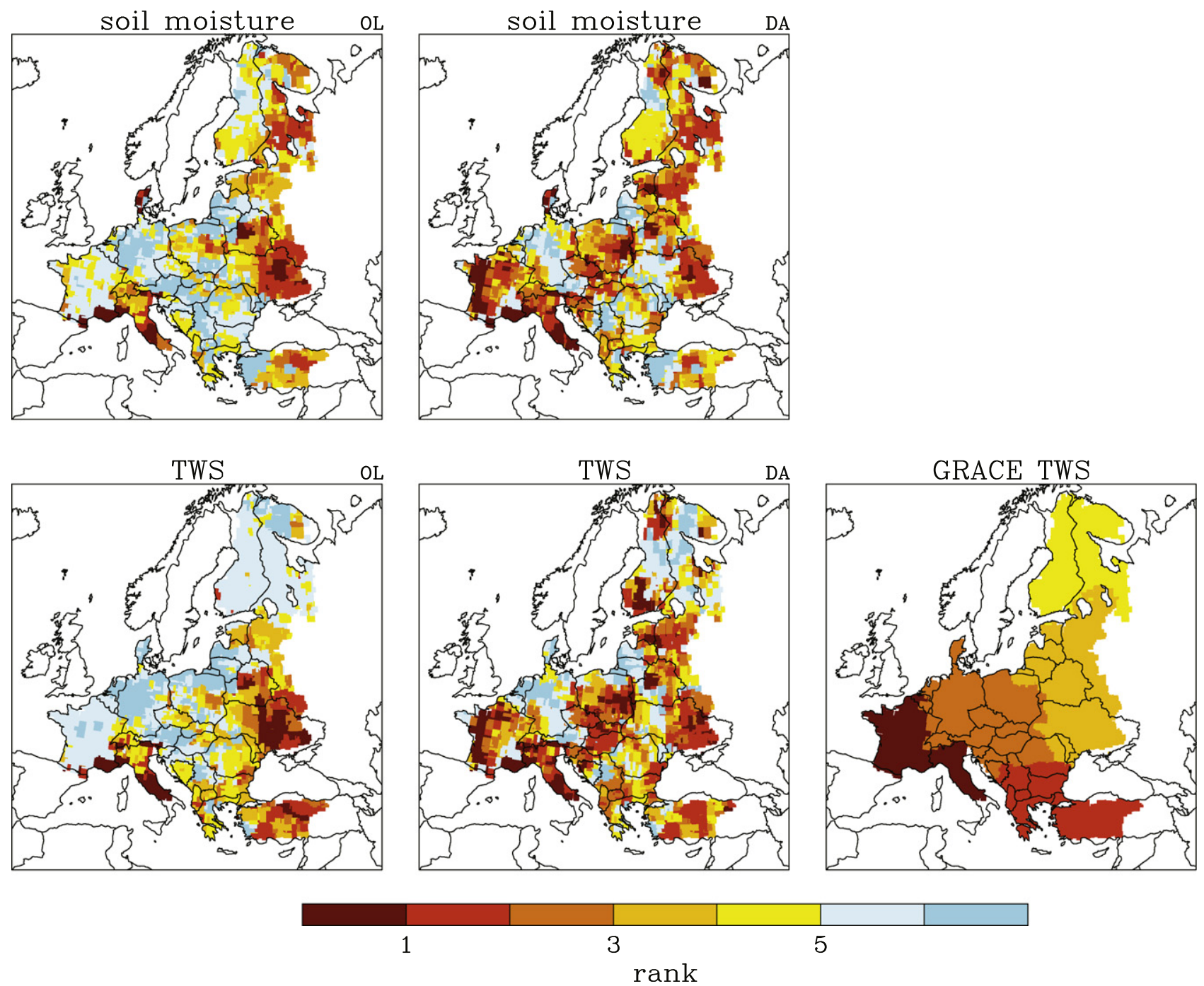

Fig. 11. Dryness ranks of simulated root zone soil moisture and TWS for November 2007 in the 2002-2009 period.

open loop, which is associated with changes in the overall temporal variability of the TWS and soil moisture fields as shown in Fig. 2. The updates in both the root zone soil moisture and TWS demonstrate that data assimilation makes it possible to apply GRACE for monitoring both agricultural and hydrological droughts, and to do so with much greater spatial resolution than with GRACE alone.

\section{Summary and discussions}

This study demonstrated the value of GRACE TWS for correcting errors in model estimated TWS and its influence on related land surface processes. In particular, assimilation significantly improved runoff correlation in most basins, which attests to the overall robustness of the assimilation technique. The improved runoff correlation in small watersheds also shows the potential of GRACE TWS to contribute to simulation of finer scale hydrological processes through data assimilation based downscaling. Assimilation of GRACE TWS did not improve the correlation of soil moisture with in situ measurements, perhaps due to the short in situ data record or insufficient spatial sampling. GRACE data assimilation had large influences on groundwater and its seasonality in several basins which are important for water resource management and drought monitoring. Although groundwater was not validated directly due to the lack of in situ measurements, the improvements in stream flow estimates suggest more realistic estimates of subsurface water storage, which controls baseflow. GRACE data assimilation also reduced interannual trends in modeled TWS and runoff. The original inconsistency between the GRACE and OL trends is caused by deficiencies in either the model's physics, the forcing data, or the GRACE data themselves. The case presented here represents a relatively short period during which annual precipitation increased at a much higher rate in several basins than long term annual precipitation trends (Mishra and Cherkauer, 2010; Solomon et al., 2007). The fact that GRACE TWS was able to change the trend in runoff suggests that GRACE TWS data, if independently validated, may assist in model and forcing evaluation and calibration, which is an important part of climate prediction (Mishra and Cherkauer, 2010), especially in regions with scarce observational data. However, only models able to simulate groundwater storage can take full advantage of GRACE, because assimilation of GRACE TWS requires an analogous model state.

Monitoring of droughts has suffered from lack of reliable information on the water stored below the uppermost soil layer. Since GRACE measures the water storage changes in the entire profile, it provides valuable information on drought development beyond what can be seen at the surface. The continued monitoring of dry conditions throughout all seasons, which cannot be achieved 
using vegetation based indicators, may further assist in tracking prolonged droughts and/or providing early signs of drought development.

While data assimilation of GRACE TWS helps to fill the need for regional to global scale information on deep moisture storage variability, it also presents some challenges. Since drought indices are derived based on the long term climatology of a given variable (Mo, 2008) and the GRACE period is not long enough to generate its own climatology, GRACE based drought indices must be linked to a model simulation that begins well before the onset of data assimilation. This requires that the estimates from the GRACE assimilation have the same dynamic range as GRACE, so that the anomalies from the assimilation period are comparable to the climatology. To accomplish this, it may be necessary to modify parameters such as the bedrock depth, which controls the amount of water available from storage to be lost during a drought. The changing trends in DA TWS, as found in this study, may also reduce the dynamic range and the magnitude of anomalies and thus present a new challenge. Statistical techniques such as scaling and cumulative distribution function matching may also be used to ensure that the modeled and observed climatologies are consistent prior to generating drought indices. Nevertheless, these challenges should not discourage the use of GRACE data assimilation for drought monitoring because the dryness information provided by GRACE TWS can lead to more objective and reliable drought indices (Rodell, 2012).

Water budget imbalance caused by GRACE data assimilation is an important issue for future research because existing flux biases may be exacerbated (assuming precipitation forcing data were accurately estimated). In this example, we speculate, without the benefit of ET and runoff observations in Finland and Loire/Seine regions, that a low bias in modeled ET and runoff might have caused the TWS anomaly to be elevated, which, when corrected by GRACE data assimilation, further reduced ET and/or runoff. This water budget imbalance might have been avoided if observations of ET and runoff were available and assimilated simultaneously with GRACE TWS. Given that ET and runoff observations are rarely assimilated into land surface models, a more likely solution would be to remove excess TWS during the assimilation process through increases in ET and/or runoff. To accomplish this and yet avoid unintended consequences such as exacerbation of flux errors and ratios between fluxes, scientists will be challenged to develop innovative assimilation strategies (Li et al., 2012; Zaitchik and Rodell, 2009).

\section{Acknowledgements}

This work was supported by funds from NASA's Terrestrial Hydrology Program. We thank GRDC and Meteo-France for providing validation data used in this study. Joseph Nigro provided assistance in creating the major basins. Barton Forman read a draft of this manuscript and provided useful comments. We appreciate the constructive comments and suggestions provided by the two reviewers which have helped improve the quality of this paper.

\section{References}

Adler, R.F., Huffman, G.J., Chang, A., Ferraro, R., Xie, P., Janowiak, J., Rudolf, B., Schneider, U., Curtis, S., Bolvin, D., Gruber, A., Susskind, J., Arkin, P., 2003. The version 2 Global Precipitation Climatology Project (GPCP) monthly precipitation analysis (1979-present). J. Hydrometerol. 4, 1147-1167.

Bierkens, M.F.P., van Beek, L.P.H., 2009. Seasonal predictability of European discharge. NAO and hydrological response time. J. Hydrometeorol. 10, 953-968.

Bloom, S., da Silva, A., Dee, D., Bosilovich, M., Chern, J.-D., Pawson, S., Schubert, S., Sienkiewicz, M., Stajner, I., Tan, W.-W., Wu, M.-L., 2005. Documentation and Validation of the Goddard Earth Observing System (GEOS) Data Assimilation System. Version 4, Tech. Rep. Ser. Global Model. Data Assimil. 104606, 26,
Global Model. and Assimil. Off., NASA Goddard Space Flight Cent., Greenbelt, MD, 187p.

Brown, J.F., Wardlow, B.D., Tadesse, T., Hayes, M.J., Reed, B.C., 2008. The vegetation drought response index (VegDRI): a new integrated approach for monitoring drought stress in vegetation. GISci. Remote Sens. 45 (1), 16-46.

Calvet, J.-C., Fritz, N., Froissard, F., Suquia, D., Petitpa, A., Piguet, B., 2007. In situ soil moisture observations for the CAL/VAL of SMOS: the SMOSMANIA network. In: Geoscience and Remote Sensing Symposium, IGARSS 2007. IEEE International.

Dirmeyer, P.A., 2000. Using a global soil wetness dataset to improve seasonal climate simulation. J. Clim. 13, 2900-2922.

Dirmeyer, P.A., Schlosser, C.A., Brubaker, K.L., 2009. Precipitation, recycling, and land memory: an integrated analysis. J. Hydrometeorol. 10, 278-288.

Ducharne, A., Koster, R.D., Suarez, M.J., Stieglitz, M., Kumar, P., 2000. A catchmentbased approach to modeling land surface processes in a general circulation model 2. Parameter estimation and model demonstration. J. Geophys. Res. 105 (D20), 24823-24838.

Eltahir, E.A.B., Yeh, P.J.-F., 1999. On the asymmetric response of aquifer water leve to floods and droughts in Illinois. Water Resour. Res. 35 (4), 1199-1217.

Fekete, B.M., Vorosmarty, C.J., Roads, J., Willmott, C.J., 2004. Uncertainties in precipitation and their impacts on runoff estimates. J. Clim. 17, 294-304.

Forman, B.A., Reichle, R.H., Rodell, M., 2012. Assimilation of terrestrial water storage from GRACE in a snow-dominated basin. Water Resour. Res. 48, W01507. http://dx.doi.org/10.1029/2011WR011239.

Gottschalck, J., Meng, J., Rodell, M., Houser, P., 2005. Analysis of multiple precipitation products and preliminary assessment of their impact on global land data assimilation system land surface states. J. Hydrometeorol. 6, 573-598.

Helsel, D.R., Hirsch, R.M., 1992. Statistical Methods in Water Resources. Elsevier Amsterdam, 522p.

Hoerling, M., Lettenmaier, D., Cayan, D., Udall, B., 2009. Reconciling projections of colorado river streamflow. Southwest Hydrol. (May/June), 20-31.

Jackson, C.R., Meister, R., Prudhomme, C., 2011. Modelling the effects of climate change and its uncertainty on UK Chalk groundwater resources from an ensemble of global climate model projections. J. Hydrol. 399, 12-28.

Karnieli, A., Agam, N., Pinker, R.T., Anderson, M., Imhoff, M.L., Gutman, G.G., Panov, N., Goldberg, A., 2010. Use of NDVI and land surface temperature for drought assessment: merits and limitations. J. Clim. 23, 618-633.

Koster, R.D., Suarez, M.J., 2001. Soil moisture memory in climate models. J. Hydrometeorol. 2, 558-570.

Koster, R.D., Suarez, M.J., Ducharne, A., Stieglitz, M., Kumar, P., 2000a. A catchmentbased approach to modeling land surface processes in a general circulation model. 1. Model structure. J. Geophys. Res. 105, 24809-24822.

Koster, R.D., Suarez, M.J., Heiser, M., 2000b. Variance and predictability of precipitation at seasonal-to-interannual timescales. J. Hydrometeorol. 1, 26-46.

Koster, R.D., Guo, Z., Yang, R., Dirmeyer, P.A., Mitchell, K., Puma, M.J., 2009. On the nature of soil moisture in land surface models. J. Clim. 22, 4322-4335.

Koster, R.D., Mahanama, S.P.P., Livneh, B., Lettenmaier, D.P., Reichle, R.H., 2010. Skill in streamflow forecasts derived from large-scale estimates of soil moisture and snow. Nat. Geosci. 3, 613-616.

Lettenmaier, D.P., Wood, E.F., Wallis, J.R., 1994. Hydroclimatological trends in the continental United States, 1948-1988. J. Clim. 7, 586-607.

Li, B., Toll, D., Zhan, X., Cosgrove, B., 2012. Improving simulated soil moisture fields through assimilation of AMSR-E soil moisture retrievals with an ensemble Kalman filter and a mass conservation constraint. Hydrol. Earth Syst. Sci. 16 105-119. http://dx.doi.org/10.5194/hess-16-105-2012, 2012.

Miguez-Macho, G., Fan, Y., Weaver, C.P., Walko, R., Robock, A., 2007. Incorporating water table dynamics in climate modeling: 2 . Formulation, validation, and soil moisture simulation. J. Geophys. Res. 112. http://dx.doi.org/10.1029/ 2006JD008112.

Mishra, V., Cherkauer, K.A., 2010. Assessment of drought due to historic climate variability and projected future climate change in the Midwestern United States. J. Hydrometeorol. 11, 46-68.

Mitchell, K.E. et al., 2004. The multi-institution North American Land Data Assimilation System (NLDAS): utilizing multiple GCIP products and partners in a continental distributed hydrological modeling system. J. Geophys. Res. 109, D07S90. http://dx.doi.org/10.1029/2003JD003823.

Mo, K.C., 2008. Model-based drought indices over the United States. J. Hydrometeorol. 9, 1212-1230.

Niu, G.-Y., Yang, Z.-L., Dickinson, R.E., Gulden, L.E., 2005. A simple TOPMODEL-based runoff parameterization (SIMTOP) for use in global climate models. J. Geophys. Res. 110, D21106. http://dx.doi.org/10.1029/2005JD006111.

Niu, G.Y., Yang, Z., Dickinson, R.E., Gulden, L.E., Su, H., 2007. Development of a simple groundwater model for use in climate models and evaluation with gravity recovery and climate experiment data. J. Geophys. Res. 112, D07103. http://dx.doi.org/10.1029/2006JD007522.

Okkonen, J., Kløve, B., 2011. A sequential modelling approach to assess groundwater-surface water resources in a snow dominated region of Finland. J. Hydrol. 411, 91-107.

Pan, M., Wood, E.F., 2006. Data assimilation for estimating the terrestrial water budget using a constrained ensemble Kalman filter. J. Hydrometeorol. 7 (3), 534-547.

Peters, E., van Lanen, H.A.J., Torfs, P.J.J.F., Bier, G., 2005. Drought in groundwater drought distribution and performance indicators. J. Hydrol. 306, 302-317.

Poulin, A., Brissette, F., Leconte, R., Arsenault, R., Malo, J.S., 2011. Uncertainty of hydrological modelling in climate change impact studies in a Canadian, snowdominated river basin. J. Hydrol. 409, 626-636. 
ARTICLE IN PRESS

B. Li et al./Journal of Hydrology $x x x(2012) x x x-x x x$

13

Rebetez, M., Mayer, H., Dupont, O., Schindler, D., Gartner, K., Kropp, J.P., Menzel, A., 2006. Heat and drought 2003 in Europe: a climate synthesis. Ann. Forest Sci. 63, 569-577.

Reichle, R.H., Koster, R.D., Lu, P., Mahanama, S.P.P., Njoku, E.G., Owe, M., 2007. Comparison and assimilation of global soil moisture retrievals from the advanced microwave scanning radiometer for the earth observing system (AMSR-E) and the scanning multichannel microwave radiometer (SMMR). J. Geophy. Res. 112, D09108. http://dx.doi.org/10.1029/2006JD008033.

Rodell, M., 2012. Satellite gravimetry applied to drought monitoring. In: Wardlow, B., Anderson, M., Verdin, J. (Eds.), Remote Sensing of Drought: Innovative Monitoring Approaches. CRC Press/Taylor and Francis, Bock Baton, pp. 261-280.

Rodell, M., Famiglietti, J.S., 2001. An analysis of terrestrial water storage variations in Illinois with implications for the gravity recovery and climate experiment (GRACE). Water Resour. Res. 37 (5), 1327-1339.

Rodell, M. et al., 2004. The global land data assimilation system. Bull. Am. Meteorol. Soc. $85,381-394$.

Rodell, M., Chen, J., Kate, H., Famiglietti, J., Nigro, J., Wilson, C., 2007. Estimating ground water storage changes in the Mississippi River basin (USA) using GRACE. Hydrogeol. J. 15, 159-166. http://dx.doi.org/10.1007/s10040-006-0103-7.

Rowlands, D.D. et al., 2005. Resolving mass flux at high spatial and temporal resolution using GRACE intersatellite measurements. Geophy. Res. Lett. 32, L04310. http://dx.doi.org/10.1029/2004GL021908.

Schaake, J.C., Koren, V., Dian, Q., Mitchell, K., Chen, F., 1996. Simple water balance model for estimating runoff at different spatial and temporal scales. J. Geophys. Res. 101 (D3), 7461-7475.

Schaller, M.F., Fan, Y., 2009. River basins as groundwater exporters and importers: implications for water cycle and climate modeling. J. Geophys. Res. 114, D04103. http://dx.doi.org/10.1029/2008JD010636.

Sen, P.K., 1968. Estimates of the regression coefficient based on Kendall's tau. J. Am. Stat. Assoc. 63, 1379-1389.

Solomon, S., Quin, D., Manning, M., Chen, Z., Marquis, M., Averyt, K.B., Tignor, M., Miller, H.L. (Eds.), 2007. IPCC Forth Assessment Report/Climate Change 2007: The Physical Science Basis. Cambridge University Press, 996p.

Steiner, J.H., 1980. Tests for comparing elements of a correlation matrix. Psychol. Bull. 87, 245-251.

Svoboda, M., LeComte, D., Hayes, M., Heim, R., Gleason, K., Angel, J., Rippey, B., Tinker, R., Palecki, M., Stooksbury, D., Miskus, D., Stephens, S., 2002. The drought monitor. Bull. Am. Meteorol. Soc. 83 (8), 1181-1190.

Swanson, S., Wahr, J., 2006. Post-processing removal of correlated errors in GRACE data. Geophys. Res. Lett. 33, L08402. http://dx.doi.org/10.1029/2005GL025285.
Swenson, S.C., Yeh, P.J.-F., Wahr, J., Famiglietti, J.S., 2006. A comparison of terrestrial water storage variations from GRACE with in situ measurements from Illinois. Geophys. Res. Lett. 33, L16401. http://dx.doi.org/10.1029/2006GL026962.

Synthesis, S.O.E.R., 2010. The European Environment - State and Outlook 2010: Synthesis. European Environment Agency, Copenhagen.

Tapley, B.D., Bettadpur, S., Res, J.C., Thompson, P.F., Watkins, M.M., 2004. GRACE measurements of mass variability in the earth system. Science 305, 503-505.

Tucker, C.J., 1979. Red and photographic infrared linear combinations for monitoring vegetation. Remote Sens. Environ. 8, 127-150.

Van Sickle, J., 2005. Errata: analyzing correlations between stream and watershed attributes. J. Am. Water Res. Assoc. (JAWRA) 41 (3), 741.

Wu, W., Geller, M.A., Dickinson, R.E., 2002. The response of soil moisture to longterm variability of precipitation. J. Hydrometeorol. 3 (12), 604-613.

Xe, P., Arkin, P.A., 1997. Global precipitation: a 17-year monthly analysis based on gauge observations, satellite estimates and numerical model outputs. Bull. Am. Meteorol. Soc. 78, 2539-2558.

Yeh, P.J.F., Eltahir, E.A.B., 2005. Representation of water table dynamics in a land surface scheme. Part I: model development. J. Clime. 18 (12), 1861-1880.

Yeh, P.J.F., Swenson, S.C., Famiglietti, J.S., Rodell, M., 2006. Remote sensing of groundwater storage changes in illinois using the gravity recovery and climate experiment (GRACE). Water Resour. Res. 42, W12203. http://dx.doi.org/ 10.1029/2006WR005374.

Yin, X., Gruber, A., Arkin, P.A., 2004. Comparison of the GPCP and CMAP merged gauge-satellite monthly precipitation products for the period 1979-2001. J. Hydrometeorol. 5, 1207-1222.

Ye, S., Wang, C.Y., 2002. Regional streamflow trend detection with consideration of both temporal and spatial correlation. Int. J. Climatol. 22, 933-946.

Zaitchik, B.F., Rodell, M., 2009. Forward-looking assimilation of MODIS-derived snow covered area into a land surface model. J. Hydrometeorol. 10 (1), 130-148.

Zaitchik, B.F., Macalady, A.K., Bonneau, L.R., Smith, R.B., 2006. Europe's 2003 heat wave: a satellite view of impacts and land-atmosphere feedbacks. Int. J. Climatol. 26, 743-769.

Zaitchik, B.F., Rodell, M., Reichle, R.H., 2008. Assimilation of GRACE terrestrial water storage data into a land surface model: results for the Mississippi river basin. J. Hydrometeorol. 9, 535-548.

Zampieri, M., Serpetzoglou, E., Anagnostou, E.N., Nikolopoulos, E.I., Papadopoulos, A., 2012. Improving the representation of river-groundwater interactions in land surface modeling at the regional scale: observational evidence and parametrization applied in the community land model. J. Hydrol. 420-421, $72-86$.

Please cite this article in press as: Li, B., et al. Assimilation of GRACE terrestrial water storage into a land surface model: Evaluation and potential value for drought monitoring in western and central Europe. J. Hydrol. (2012), http://dx.doi.org/10.1016/j.jhydrol.2012.04.035 